\title{
In Situ $\alpha$-Alumina Hydrophobization Dynamics at Acid pH: Effectiveness Limitations of Short-chain Amphiphilic Molecules
}

\author{
D. O. Vivaldini, A. P. Luz*, V. R. Salvini, V. C. Pandolfelli \\ Materials Microstructure Engineering Group - GEMM, Materials Engineering Department, \\ Federal University of São Carlos - UFSCar, Rod. Washington Luiz, Km 235, CP 676, \\ CEP 13565-905, São Carlos, SP, Brazil
}

Received: April 17, 2013; Revised: August 8, 2013

\begin{abstract}
The present work highlights that $\alpha$-alumina hydrophobicity (attained by the in situ modification of its surface properties with water soluble organic monoacids) cannot be increased by using molecules with low acidity $(\mathrm{pKa})$ values due to the alumina zeta potential profile at $\mathrm{pHs}$ below approximately 4 . In order to certify this statement, the effects of short-chain fatty acids and fluorinated ones on the alumina contact angle $(\theta \mathrm{e})$ with water were analyzed. It is also pointed out that the $\theta \mathrm{e}$ values derived from the experiments carried out using fluorinated acids are the highest possible when monoacid surfactants are added in $\alpha$-alumina suspensions in acidic $\mathrm{pH}$. This result indicates that there is another constraint to the in situ hydrophobization procedure, which was not previously elucidated or fully settled in literature.
\end{abstract}

Keywords: hydrophobization, contact angle, $p K a$, alumina

\section{Introduction}

The surface modification of oxide particles has been studied over the latest decades due to the relevant role of the physico-chemical properties on technological advances ${ }^{1}$. The stabilization of foams/emulsions using particles and many related fundamental concepts have been evaluated and proposed by many authors ${ }^{2,3}$. The contact angle, also known as the equilibrium wetting angle $(\theta e)$ of oxide compounds seems to be a key parameter for foam generation and its stability ${ }^{4.5}$. Investigations have shown that highly hydrophilic $\left(\theta \mathrm{e}<30^{\circ}\right)$ or highly hydrophobic $\left(\theta \mathrm{e}>120^{\circ}\right)$ particles are not suitable as foam stabilizers. Therefore, in order to produce high stable foams, the contact angle value must vary within an optimized range $e^{6,7}$, which can be achieved by successfully modifying the particles' surface.

The most usual way to change a ceramic surface is the in situ modification processes ${ }^{8-10}$. However, such transformations need to take place in aqueous suspension, otherwise it could be very difficult to disperse the modified particles 8 . One possible route to induce the hydrophobization of alumina particles in suspension is by the addition of specific organic water-soluble molecules that can be adsorbed to the oxide surface and reduce its affinity for water molecules. Using this technique, Gonzenbach et al. ${ }^{11}$ prepared particle stabilized ceramic foams by adding short chain acid molecules to an alumina suspension. Table 1 shows some of their results, related to the $\alpha$-alumina hydrophobization process with three different short-chain acids.

Based on Table 1, it can be observed that the longer the hydrophobic chain length, the higher the $\theta \mathrm{e}$ value ${ }^{12}$. It must also be pointed out that the unmodified $\alpha$-alumina surface has an equilibrium wetting angle of approximately $20^{\circ}$.

*e-mail: anapaula.light@gmail.com
The chemical mechanism leading to this transformation is based on the ionization of the carboxylic acids in aqueous solution which releases a proton of their head group, resulting in a remaining negatively charged molecule (an anionic specie) ${ }^{13}$. On the other hand, the alumina surface charge depends on the $\mathrm{pH}$ of the suspension which below its isoelectric point (approximately 9 - Figure 1) is positive. Therefore, the carboxylic acid anion will be attached to the positively charged alumina surface groups via electrostatic interactions at acidic $\mathrm{pHs}^{[11,14]}$.

The most important physicochemical property of carboxylic acids in solution regarding their adsorption capacity onto solid surfaces seems to be their pKa values, also known as the molecule acidity ${ }^{13,15}$. This parameter defines the amount of dissociated molecules in solution able to be adsorbed at the particle's surface. Figure 2, for instance, shows the percentage of adsorbed molecules of propionic acid on the alumina surface as a function of the suspension $\mathrm{pH}^{[15]}$. The maximum adsorption was identified at the same $\mathrm{pH}$ range of the molecule's pKa ( 4.8). The adsorbed amount decreases for the lower $\mathrm{pH}$ as less acid molecules are deprotonated, decreasing the number of molecules available to adsorption. On the other hand, for $\mathrm{pH}>4.8$, there are less available sites at the alumina surface as the zeta potential values decrease continuously until its point of zero charge $(\mathrm{pH} \sim 9 \text {, see Figure } 1)^{16}$. Therefore, this dynamic process defines the adsorption likelihood at the alumina surface and, consequently, the modifier's ability to increase the $\theta \mathrm{e}$ value.

Figure 2 depicts an important aspect of the hydrophobization procedure, highlighting that there is an optimized $\mathrm{pH}$ range that maximizes the amount of adsorbed molecules at the particles surface. 
Table 1. $\alpha$-Alumina equilibrium contact angle $\left(\theta_{\mathrm{e}}\right)$ modified by the addition of three different acids at room temperature (Concentration: $10 \mathrm{mM}$ and $\mathrm{pH}=4.8)^{18,22}$.

Acid Name Molecular Structure



Figure 1. $\alpha$-Alumina zeta potential $(\xi)$ as a function of $\mathrm{pH}^{[23]}$. The analyzed alumina powder was supplied by the Sumitomo Chemical Company and presented the following features: $d_{50}=0.4 \mu \mathrm{m}, 99.99 \%$ purity and specific surface area of $7 \mathrm{~m}^{2} \mathrm{~g}^{-1}$.

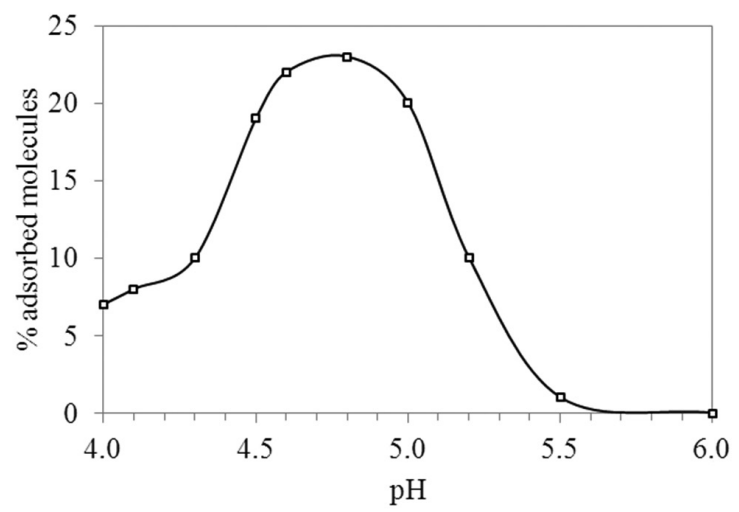

Figure 2. Percentage of adsorbed propionic acid molecules on alumina surface, as shown by Hidber et al. ${ }^{15}$.
Regarding the control of the in situ hydrophobization process of the alumina particles, there are three key aspects to be considered, which are summarized as follows:

- Chain-length: the longer the surfactants hydrophobic tail, the higher the $\theta \mathrm{e}$ value attained at a fixed concentration (as presented in Table 1). Unfortunately, the use of molecules with very long-chain lengths is not advisable due to their reduced water solubility and detrimental effects for suspension rheology, leading to a significant increase in the viscosity, as shown by Chuanuwatanakul et al. ${ }^{17}$ and Gonzenbach et al. ${ }^{11}$;

- $\mathrm{pKa}-\mathrm{pH}$ relation: at a given $\mathrm{pH}$, the lower the $\mathrm{pKa}$ value, the higher the amount (Figure 2) of available surfactant molecules to carry out adsorption and, thus, surface modification ${ }^{15}$. For the oxide particles, the higher the zeta potential, the higher the number of sites available for adsorption;

- Concentration: at a fixed $\mathrm{pH}$, the higher the surfactant concentration, the higher the $\theta \mathrm{e}$ value achieved at the particle's surface. Nevertheless, MegiasAlguacil et al. ${ }^{18}$ showed the modifier's concentration scales with the contact angle $\left(\theta_{\mathrm{e}}\right)$ up to a maximum value. Hence, very high concentrations of acids can lead to $\theta$ e decrease. Above a critical amount, the acid molecule adsorption is carried out in a multilayer fashion, which reduces the hydrophobizing effect as the polar groups of the secondary layers add charge to the system (rendering it more hydrophilic). Moreover, the acid concentration at the $\theta$ e maximum value is not always used in practice due to the high viscosity of such systems ${ }^{14,18}$.

Thus, the only approach to enhance the adsorption process of acid molecules at the alumina surface, given a fixed concentration and chain-length, is to use molecules with lower $\mathrm{pKa}$ values. The literature ${ }^{15}$ indicates that the lower the $\mathrm{pKa}$ value and the lower the $\mathrm{pH}$ suspension, the higher the adsorption likelihood would be and, therefore, the higher $\theta_{\mathrm{e}}$ values should be attained. Hence, the main objective of this work is to highlight that the selection of molecules with low pKa values may also face some limitations, as a maximum threshold for the $\theta \mathrm{e}$ value may exist. In order to evaluate these limits, this work compared the hydrophobization efficiency of fatty and fluorinated acids (based on experimental data presented in the literature) on the $\alpha$-alumina surface using fundamental adsorption concepts and mathematical procedures.

\section{Mathematical Approaches}

Equation 1 can be used to calculate the fraction of deprotonated molecules as a function of the suspension $\mathrm{pH}$ and the pKa value of an acid molecule ${ }^{19,20}$.

$$
\frac{\left[R^{-}\right]}{[R]}=1-\frac{1}{1+10^{p H-p K a}}
$$

where, $[R]$ is the total amount of molecules, $\left[\mathrm{R}^{-}\right]$is their deprotonated content and $\frac{\left[R^{-}\right]}{[R]}$ is the fraction ratio of deprotonated molecules in solution. This mathematical 
expression can provide important information such as the amount of organic molecules that will be available to react and adsorb on a solid surface.

The wetting data can be obtained as a function of the advancing $\left(\theta_{A}\right)$ and receding $\left(\theta_{R}\right)$ contact angles, which are not exactly equal to the equilibrium one, $\theta \mathrm{e}$. In order to compare the values of the wetting angle that were measured by different methods, one has to convert $\theta_{\mathrm{A}}$ and $\theta_{\mathrm{R}}$ into $\theta \mathrm{e}$, a procedure that can be done using Equation $2^{[21]}$.

$$
\theta_{e}=\arccos \left\{\frac{\left[\left(\frac{\sin ^{3} \theta_{A}}{2-3 \cos \theta_{A}+\cos ^{3} \theta_{A}}\right)^{\frac{1}{3}} \cos \theta_{A}+\right.}{\left[\left(\frac{\sin ^{3} \theta_{R}}{2-3 \cos \theta_{R}+\cos ^{3} \theta_{R}}\right)^{\frac{1}{3}}\right] \cos \theta_{R}}\left[\begin{array}{l}
{\left[\left(\frac{\sin ^{3} \theta_{A}}{2-3 \cos \theta_{A}+\cos ^{3} \theta_{A}}\right)^{\frac{1}{3}}+\right]} \\
{\left[\left(\frac{\sin ^{3} \theta_{R}}{2-3 \cos \theta_{R}+\cos ^{3} \theta_{R}}\right)^{\frac{1}{3}}\right]}
\end{array}\right\}\right.
$$

The $\theta_{\mathrm{A}}$ and $\theta_{\mathrm{R}}$ data obtained by Karaman et al. ${ }^{22}$ was inserted in equation 2 and the resulting $\theta \mathrm{e}$ values for the fluorinated carboxylic acids had their results compared to the fatty ones shown in Table 1. Furthermore, the dissociated fraction of the acid molecules (fatty of fluorinated ones) in suspension, calculated according to Equation 1, was correlated to the $\theta \mathrm{e}$ values.

\section{Results and Discussion}

Figure $3 \mathrm{a}$ presents the measured equilibrium contact angle for propionic $\left(\mathrm{C}_{3} \mathrm{H}_{6} \mathrm{O}_{2}\right)$, valeric $\left(\mathrm{C}_{5} \mathrm{H}_{10} \mathrm{O}_{2}\right)$, enanthic $\left(\mathrm{C}_{7} \mathrm{H}_{14} \mathrm{O}_{2}\right)^{[12]}$ and also for two types of fluorinated acids [perfluoropropionic $\left(\mathrm{C}_{3} \mathrm{HF}_{5} \mathrm{O}_{2}\right)$ and perfluoroctanoic $\left(\mathrm{C}_{8} \mathrm{HF}_{15} \mathrm{O}_{2}\right)$ ] in water (concentration $10 \mathrm{mM}$ ).

According to Figure $3 \mathrm{a}$, fluorinated acids are more effective than the fatty acids to increase the equilibrium contact angle of alumina as, given the same or similar molecular chain length, the lower the modifier's pKa value, the higher the $\theta \mathrm{e}$ attained.

In order to explain the behavior shown in Figure 3a, Equation 1 was used to calculate the amount of ionized molecules for the evaluated surfactants. The results are shown in Figure 3b, calculated for two pKa values, namely, 4.8 for the fatty acids and 0.7 for the fluorinated ones. Based on the results, at low $\mathrm{pH}$, the molecules with smaller $\mathrm{pKa}$ values present higher dissociated fraction values $\left(\frac{\left[R^{-}\right]}{[R]}\right)$.

For instance, in the $\mathrm{pH}$ range (2-4.8) where the $\theta \mathrm{e}$ values shown in Figure 3a were measured, the deprotonated fraction was approximately 50\% and between 95-99\% for the fatty acids and fluorinated ones, respectively, which justifies the higher effectiveness of the latter to induce the hydrophobization of alumina particles. This result is


Figure 3. a) $\alpha$-Alumina wetting angle as a function of the type of acid used for its surface modification ${ }^{18,22}$, where the number of carbon atoms for each molecule is presented in parenthesis. The concentration for all acids is $10 \mathrm{mM}$ and the $\mathrm{pH}$ solution was kept between 4.7-4.8 and in the 2-3 range for the fatty and fluorinated acids, respectively. b) Dissociated fraction of an acid as a function of $\mathrm{pH}$ for two $\mathrm{pKa}$ values ( 4.8 for the fatty acids and 0.7 for the fluorinated acids) calculated by Equation 1 .

further strengthened when considered that the $\alpha$-alumina zeta potential for $\mathrm{pH}$ values below 4.0 hardly increases or even decreases $(\mathrm{pH}<2)$, which indicates that the amount of available molecules to adsorb is the determinant parameter in that $\mathrm{pH}$ range. Therefore, for the alumina system, it may be impracticable to attain higher $\theta \mathrm{e}$ values than those attained by the fluorinated molecules with another sort of short-chain monoacids at $\mathrm{pH}<4.0$, even when their $\mathrm{pKa}$ value is lower, as they are already close to $100 \%$ dissociation. This aspect may indicate a limit for the $\theta$ e value range likely to be reached by the in situ hydrophobization of the alumina surface via short chain-length surfactants selection for the acid $\mathrm{pH}$ range.

Therefore, if one would carry out the hydrophobization at, for instance, $\mathrm{pH}=1$, according to Figure $3 \mathrm{~b}$, the dissociated fraction of fluorinated acids would be around $66 \%$. In that case, another surfactant with even lower pKa (e.g., -1) could result in a major increase in the available dissociated species in the medium and provide better results compared to the fluorinated acids at $\mathrm{pH}=1$. Nonetheless, it may be possible that the highest value for $\theta \mathrm{e}$ could be the same as for the fluorinated acids at $\mathrm{pH}=2-3$ (see Figure 3a), given that the molecular chain-length and concentration $(10 \mathrm{mM})$ are fixed, as in such conditions the limiting factor would be 
the number of charged groups at the alumina surface (which hardly increases or decreases at $\mathrm{pH}<4.0$ ). If the $\alpha$-alumina zeta potential curve had presented a negative slope for the entire acidic $\mathrm{pH}$ range, then the $\theta \mathrm{e}$ limit might not have been detected by the fluorinated acids at $\mathrm{pH}=2-3$. Such claim indicates another constraint to the in situ hydrophobization route not previously reported in the literature.

\section{Conclusions}

The calculations carried out in this work suggested that in order to optimize the increase of the alumina-water contact angle $(\theta \mathrm{e})$ in the low $\mathrm{pH}$ range using short-chain molecules (less than 8 carbons in its backbone), it is necessary that most of the species remain dissociated in the $\mathrm{pH}$ chosen to carry out the reaction, preferably higher than $95 \%$ of dissociation. Moreover, by comparing the alumina hydrophobization efficiency between fatty and fluorinated

\section{References}

1. Bonn D, Eggers J, Indekeu J, Meunier J, and Rolley E. Wetting and spreading. Reviews of Modern Physics. 2009; 81:739-805. http://dx.doi.org/10.1103/RevModPhys.81.739

2. Kaptay G. Interfacial criteria for stabilization of liquid foams by solid particles. Colloids and Surfaces A: Physicochemical and Engineering Aspects. 2004; 230:67-80. http://dx.doi. org/10.1016/j.colsurfa.2003.09.016

3. Kruglyakov P and Nushtayeva A. Emulsions stabilised by solid particles - The role of capillary pressure in the emulsion films. In: Emulsions: Structure, Stability and Interactions. London: Elsevier; 2004. p. 671-677. http://dx.doi.org/10.1016/S15734285(04)80018-8

4. Pugh R. Foaming, foam films, antifoaming and defoaming. Advances in Colloid and Interface Science. 1996; 64:67-142. http://dx.doi.org/10.1016/0001-8686(95)00280-4

5. Stevenson P. Foam Engineering. New York:John Wiley \& Sons; 2012. http://dx.doi.org/10.1002/9781119954620

6. Kaptay G. On the equation of the maximum capillary pressure induced by solid particles to stabilize emulsions and foams and on the emulsion stability diagrams. Colloids and Surfaces A: Physicochemical and Engineering Aspects. 2006; 282-283:387-401. http://dx.doi.org/10.1016/j. colsurfa.2005.12.021

7. Kaptay G. On the optimum contact angle of stability of foams by particles. Advances in Colloid and Interface Science. 2011; 170:87-88. PMid:22208958. http://dx.doi. org/10.1016/j.cis.2011.12.002

8. Binks B and Horozov T. Aqueous foams stabilized solely by silica nanoparticles. Angewandte Chemie International Edition. 2005; 117:3788-3791. http://dx.doi.org/10.1002/ ange. 200462470

9. Studart A R, Gonzenbach UT, Tervoort E and Gauckler LJ. Processing routes to macroporous ceramics: A review. Journal of the American Ceramic Society. 2006; 89:1771-1789. http:// dx.doi.org/10.1111/j.1551-2916.2006.01044.x

10. Ata S. Coalescence of bubbles covered by particles. Langmuir. 2008; 24:6085-6091. PMid:18484761. http://dx.doi. org/10.1021/la800466x

11. Gonzenbach UT, Studart AR, Tervoort E and Gauckler LJ. Stabilization of foams with inorganic colloidal particles. Langmuir. 2006; 22:10983-10988. PMid:17154574. http:// dx.doi.org/10.1021/la061825a acids, it can be suggested that the fluorinated ones attained the maximum $\theta \mathrm{e}$ value that short-chain monoacid surfactants can achieve for the $\alpha$-alumina surface in acidic $\mathrm{pH}$, via the in situ hydrophobization route. Therefore, besides the already known modifier concentration and the chain length effect, this work showed an additional limitation to the control of the hydrophobicity of the $\alpha$-alumina particles. Moreover, it is also important to highlight that the key aspect of the presented paper is to report the likelihood of another restriction for the in situ hydrophobization process, which can be used for foam production for many other purposes.

\section{Acknowledgments}

The authors are grateful to the Brazilian research funding institution CNPq, FIPAI and FIRE (Federation for International Refractory Research and Education) for supporting this work.

12. Hare EandZisman W A.Properties of films of adsorbed fluorinated acids. Journal of Physical Chemistry. 1954; 58:236-239. http:// dx.doi.org/10.1021/j150513a011

13. Smith M B. Organic Chemistry: An Acid-Base Approach. New York: CRC Press; 2011.

14. Gonzenbach U T, Studart A R, Tervoort E and Gauckler L J Macroporous ceramics from particle-stabilized wet foams. Journal of the American Ceramic Society. 2007; 90:16-22. http://dx.doi.org/10.1111/j.1551-2916.2006.01328.x

15. Hidber $P$, Graule $T$ and Gauckler L. Influence of the dispersant structure on properties of electrostatically stabilized aqueous alumina suspensions. Journal of the European Ceramic Society. 1997; 17:239-249. http://dx.doi.org/10.1016/S09552219(96)00151-3

16. Franks $\mathrm{G}$ and Gan Y. Charging behavior at the alumina-water interface and implications for ceramic processing. Journal of the American Ceramic Society. 2007; 90:3373-3388. http:// dx.doi.org/10.1111/j.1551-2916.2007.02013.x

17. Chuanuwatanakul C, Tallon C, Dunstan D E and Franks G V. Controlling the microstructure of ceramic particle stabilized foams: influence of contact angle and particle aggregation. Soft Matter. 2011; 7:11464-11474. http://dx.doi.org/10.1039/ c1sm06477k

18. Megias-Alguacil D, Tervoort E, Cattin C and Gauckler L. Contact angle and adsorption behavior of carboxylic acids on $\alpha-\mathrm{Al}_{2} \mathrm{O}_{3}$ surfaces. Journal of Colloid and Interface Science. 2011; 353:512-518. PMid:20970145. http://dx.doi. org/10.1016/j.jcis.2010.09.087

19. Goss K. The pKa values of PFOA and other highly fluorinated carboxylic acids. Environmental Science \& Technology. 2008; 42:456-458. http://dx.doi.org/10.1021/ es702192c

20. Cheng J, Psillakis E, Hoffmann M R and Colussi A J. Acid Dissociation versus Molecular Association of Perfluoroalkyl Oxoacids: Environmental Implications. Journal of Physical Chemistry. A. 2009; 113:8152-8156. PMid:19569653. http:// dx.doi.org/10.1021/jp9051352

21. Chibowski E and Terpilowski K. Surface free energy of sulfur - Revisited: I. Yellow and orange samples solidified against glass surface. Journal of Colloid and Interface Science. 2008; 319:505-513. PMid:18177886. http://dx.doi. org/10.1016/j.jcis.2007.10.059

22. Karaman M, Antelmi D and Pashley R. The production of stable hydrophobic surfaces by the adsorption of hydrocarbon 
and fluorocarbon carboxylic acids onto alumina substrates. Colloids and Surfaces A: Physicochemical and Engineering Aspects. 2001; 182:285-298. http://dx.doi.org/10.1016/S09277757(00)00821-9
23. Cerbelaud M, Videcoq A, Abélard P, Pagnoux C, Rossignol F and Ferrando R. Self-assembly of oppositely charged particles in dilute ceramic suspensions: predictive role of simulations. Soft Matter. 2010; 6:370-382. http://dx.doi.org/10.1039/b908671d 